\title{
In reply: Another easy method to reduce syringe swapping
}

\author{
Christopher L. Pysyk, MD, FRCPC
}

Received: 16 July 2018/ Accepted: 16 July 2018/Published online: 2 August 2018

(C) Canadian Anesthesiologists' Society 2018

\section{To the Editor,}

I thank Dr. Bloria for describing another possible way to reduce medication errors involving muscle relaxants in the perioperative environment. ${ }^{1}$ Placing the empty medication ampoule over the capped needle does change the appearance of the needle-syringe complex compared with other syringes not prepared in this manner. Nevertheless, in situations where the needle cover and ampoule are removed en bloc for the syringe to access the intravenous injection port, any potential benefit gained from physical and/or visual identification of the muscle relaxantcontaining syringe, when prepared as described by the author, ${ }^{1}$ would no longer be present.

Given that the majority of syringe swap errors involve muscle relaxants and occur at anesthesia induction ${ }^{2}$ (where a large number of medications are administered in a short period of time), it is not uncommon, for example during rapid or modified rapid sequence induction, to handle several syringes with needles and caps removed to facilitate rapid administration of the induction medications. In this setting (with needle cap and ampoule removed) the muscle relaxant syringe, as described, ${ }^{1}$ would only have the affixed drug label as the sole method of verifying the syringe contents immediately before administration. In contrast, taping the empty medication container (ampoule or vial) to the barrel of the syringe ${ }^{3}$ maintains the distinguishing visual and physical characteristics of the muscle relaxant syringe throughout the medication administration sequence.

Conflicts of interest None declared.

Editorial responsibility This submission was handled by Dr. Hilary P. Grocott, Editor-in-Chief, Canadian Journal of Anesthesia.

Funding sources No funding sources were provided or supported the work.

\section{References}

1. Bloria DS. Another easy method to reduce syringe swapping. Can J Anesth 2018; 65: this issue. DOI: https://doi.org/10.1007/s12630018-1191-2.

2. Fasting S, Gisvold SE. Adverse drug errors in anesthesia, and the impact of coloured syringe labels. Can J Anesth 2000; 47: 1060-7.

3. Pysyk CL. Differentiating muscle relaxant syringes to reduce syringe swap error. Can J Anesth 2018; 65: 850-1.
C. L. Pysyk, MD, FRCPC ( $₫)$

Department of Anesthesiology and Pain Medicine, Faculty of Medicine, University of Ottawa, Ottawa, ON, Canada

e-mail: cpysyk@toh.on.ca

C. L. Pysyk, MD, FRCPC

Department of Anesthesiology and Pain Medicine, The Ottawa

Hospital, Ottawa, ON, Canada 